\title{
A Pathological Study on Cardiac Disease Found in Spiny Lobsters
}

\author{
Shinpei Wada, ${ }^{* 1}$ Akihisa Takayama, ${ }^{* 1}$ Kishio Hatai, ${ }^{* 1}$ Yasuhiro Shima, ${ }^{* 2}$ and Hiroshi Fushimi*3 \\ ${ }^{* 1}$ Division of Fish Diseases, Nippon Veterinary and Animal Science University, Musashino, Tokyo 180, Japan \\ ${ }^{* 2}$ Minami-Izu Station, Japan Sea Farming Center, Minami-izu, Kamo, Shizuoka 415-01, Japan \\ ${ }^{* 3}$ Overseas Fishery Cooperation Foundation, Akasaka, Minato, Tokyo 107, Japan
}

(Received May 26, 1993)

\begin{abstract}
A pathological study was performed on wild spiny lobsters with cardiac disease found in captured and stored groups of such lobsters in the Minami-Izu region of Shizuoka Prefecture. The present study evaluated the microbiology and histopathology of 39 lobsters including animated and weakened individuals.

Histopathological examination revealed that all the lobsters examined had cardiac lesions showing degeneration and necrosis of muscle fibers with haemocyte infiltration. No microorganisms were detected in the cardiac lesions on which histological and cultivating examinations were performed. From the results, it was considered that a disease characterized by degeneration and necrosis of cardiac muscles resulting in myocarditis would prevail in a cluster of free-living wild spiny lobsters.
\end{abstract}

Key words: spiny lobster, cardiac disease, histopathology

Since 1988, a disease of unknown etiology has been found in stored spiny lobsters, Panulirus japonicus in the Izu region of Shizuoka Prefecture. All the diseased lobsters died within a few days after being capture. Dying lobsters which had become inactive sometimes showed edematic swelling of abdominal segments. To examine the etiology of this disease, we attempted microbiological and histopathological examinations of the weakened lobsters collected from among stored individuals, and making comparisons with animated animals. In addition, we also examined wild lobsters immediately after capture. As a result, it was found that both stored and captured wild lobsters suffered from myocarditis in varying degrees.

\section{Materials and Methods}

A total of 39 lobsters weighing $290 \mathrm{~g}$ on average were examined in this research. All the lobsters examined were captured in the region of Izu during the period from 1990 to 1991. Seven specimens were examined immediately after being transported from capture sites (wild group), while the other 32 lobsters had been stored for at least one week prior to the examination at the Minami-Izu Station of the Japan Sea Farming Center (stored group). All of the wild lobsters and 26 of the stored lobsters showed weakness in activity to some extent. Overall examination showed the other six stored lobsters were judged to be animated. The lobsters used in this study were divided into three groups, i.e. a weakened wild group (WW), a weakened stored group (WS), and an animated stored group (AS). The haemolymphs, hearts and gills of four lobsters from the WW group, and from six from the WS group were autopsied for microbiological examination. Bacterial and fungal isolations were attempted by inoculating these autopsied specimens on heart-infusion agar (HIA) and pepton-yeast extract-glucose-sea water agar (PYGSA), respectively.

All lobsters were autopsied for histopathological examination routinely. The hepatopancreas, antennal glands, hearts, stomachs, hindguts, gonads, abdominal trank muscles and gills were dissected and fixed in a $10 \%$ phosphate buffered formalin solution. The fixed tissues were processed into paraffin and $4-5 \mu \mathrm{m}$ sections which were stained with heamatoxylin and eosin (H\&E). Some selected sections were also stained with periodic acid Schiff reaction (PAS), Giemsa, Ziehl-Neelsen method (ZN) and Gomori's methenamine silver nitrate Grocott's variation (Grocott). To evaluate the obtained histopathological findings, $\chi^{2}$ analysis was performed between the findings and clinical signs using $2 \times 2$ contigency tables (Tables 1 and 2).

A portion of the hearts and hepatopancreas from 30 (seven of WW, 20 of WS, and three of AS) out of the 39 lobsters were also dissected and fixed in a cold $2 \%$ paraformaldehyde- $3.2 \%$ glutaraldehyde fixative for 24 hours. Thereafter the tissues were post-fixed for 2 hours in cold $1 \%$ osmium tetroxide. After dehydration in graded alcohols, the tissues were embedded in Epon 812. Thin sections were stained with uranyl acetate and lead citrate. These thin sections were then examined with a JEM $100 \mathrm{CX}$ electron microscope.

\section{Results}

\section{Gross Pathology}

The lobsters examined, which were classified into WW and WS groups, showed varying degrees of weakness. Handling could induce some lobsters of the WS group which showed severe weakness to die. Seven (one WW and six WS) of the 39 weakened lobsters showed edematic swelling of their abdominal segments (Fig. 1), and all of them showed severe weakness as well. In the seven lobsters, two of the WS group had white nodules on their hearts (Fig. 2). Although one lobster of the WW group had injuries on the carapaces and three lobsters of the WS group showed black gill lesions, these findings were not common characteristics of all weakened lobsters.

\section{Microbiological Examination}

Two kinds of bacteria were isolated from the heaemolymph of two of 10 examined lobsters but both were classified as genus Vibrio. Oomycete fungus was also isolated from the gill filaments of one of the 10 lobsters examined. No microorganisms were isolated from other specimens.

\section{Histopathological Examination}

Degenerated and necrotized areas of cardiac muscles were found in the hearts of the 39 lobsters examined, in varying degrees. These included such conditions as coagulative necrosis of cardiac muscles with hyaline degeneration (Fig. 


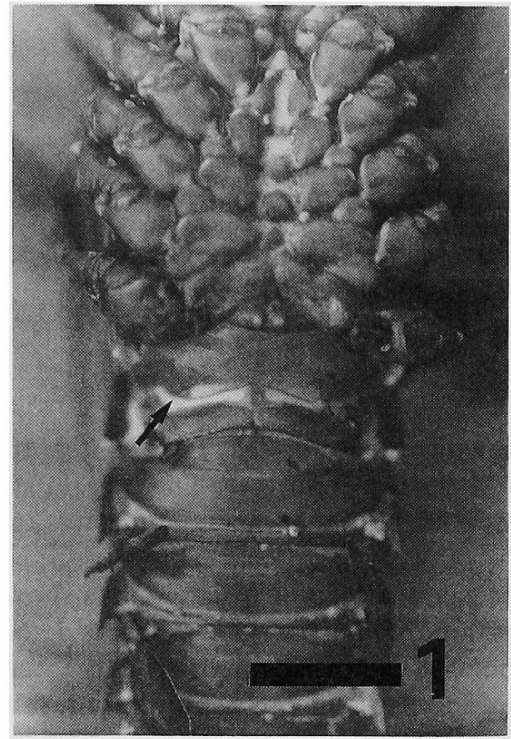

Fig. 1. Edematic lesion in the abdominal segments (arrow) of a severely weakened lobster.

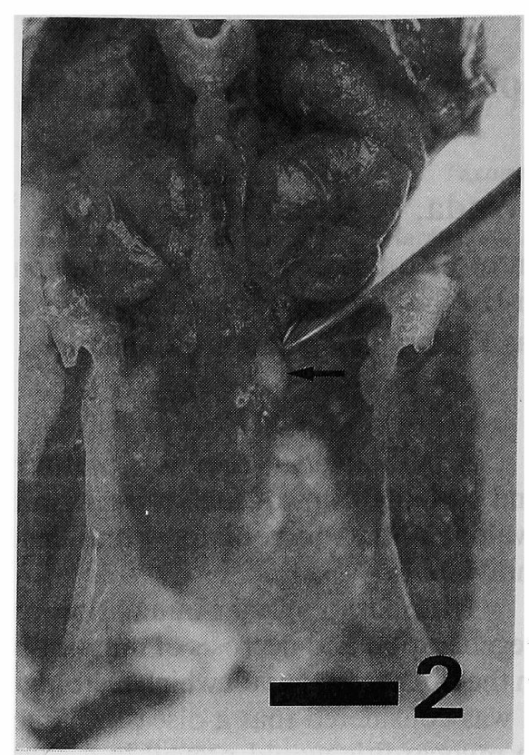

Fig. 2. White nodular lesion (arrow) occurred in the heart of severely weakened lobster.

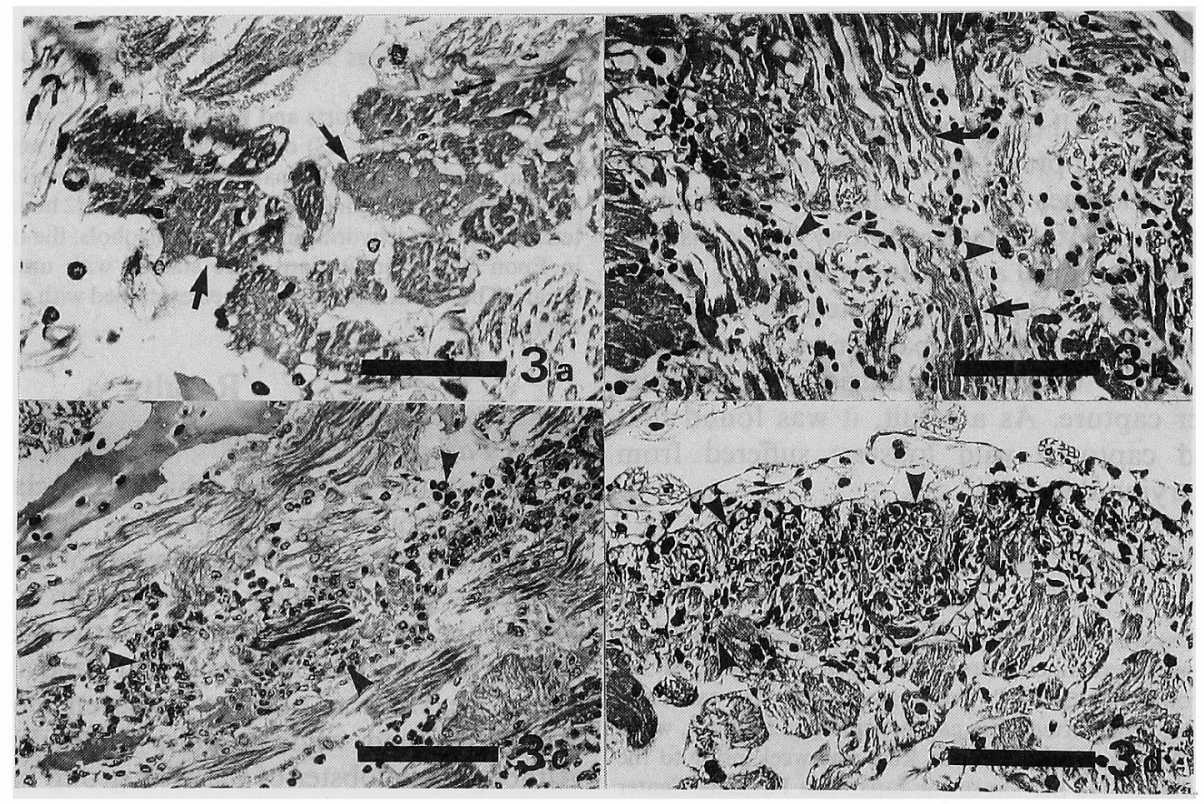

Fig. 3. Various cardiac changes occurred in examined lobsters.

a. Coagulative necrosis of muscle fibers (arrows) followed by hyalinization. $\mathrm{H} \& \mathrm{E}$, bar $=47 \mu \mathrm{m}$.

b. Atrophic muscle fibers (arrows) with infiltration of haemocytes (arrow heads). H \& E, bar $=190 \mu \mathrm{m}$.

c. Extensively necrotized muscle fibers followed by marked infiltration of haemocytes (arrow heads). H \& E, bar $=190 \mu \mathrm{m}$.

d. Extensive necrotic lesion showing haemocyte (arrow heads) infiltration in necrotic muscle fibers. $\mathrm{H} \& \mathrm{E}, \mathrm{bar}=95 \mu \mathrm{m}$.

3a), atrophy of cardiac muscles with infiltrating haemocytes between the necrotized cardiac muscles (Fig. 3b, c), and widely necrotized cardiac muscles with infiltrated haemocytes in severe lesions (Fig. 3d).

The white nodules that occurred in some hearts were severe myocarditis lesions which were replaced with irregularly arranged bundles of spindle-shaped cells, necrotized muscle fibers and cellular debris (Fig. 4a, b). Eosinophilic granular cells were scattered over the lesions.

These cardiac lesions were observed not only in the WS group, bur also in the WW and AS groups. Although two lobsters in the AS group had severe cardiac lesions, severe lesions were observed more frequently in lobsters showing severe weakness. The results of $\chi^{2}$ analysis also suggested that the more severe clinical signs the lobsters showed, the greater the severity of cardiac lesions found in the lobsters $(p<0.05)$ (Tables 1 and 2). Edematic swelling of the abdominal segments were observed in lobsters with moderate or severe cardiac lesion; however, we were not able to show a relationship between the cardiac lesions and 


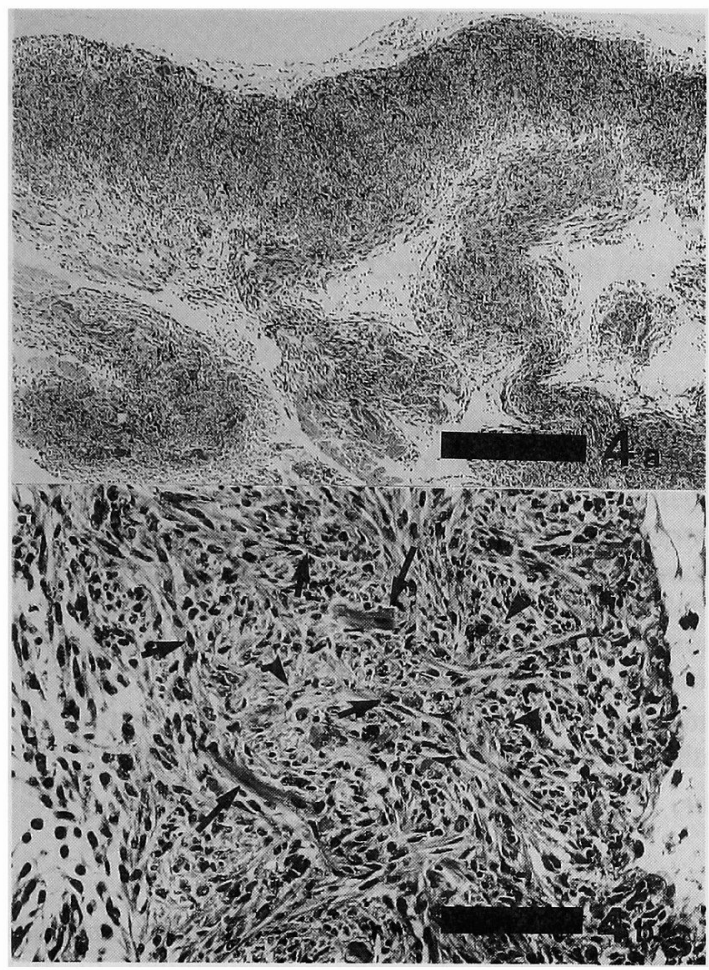

Fig. 4. Severe cardiac lesions in the nodular lesions of the heart.

a. Myocarditis lesions extend widely in the myocardium. H \& E bar $=436 \mu \mathrm{m}$

b. Detail of a myocarditis lesion. The lesion is replaced with irregularly arranged bundles of spindle-shaped cells, necrotized fiber (arrows) and the debris (arrow heads). H \& E, bar $=79 \mu \mathrm{m}$.

edematic swelling of the abdominal segments. Light and electron microscopical examination did not show any microorganisms in the hearts or hepatopancreas, and light microscopy showed no lesions in the other organs examined without the granulomatous mycotic lesions in the gills of the three lobsters of WS.

\section{Discussion}

In the present case, various degrees of degeneration and necrosis of cardiac muscles associated with infiltrated haemocytes were found in the lobsters examined. Histopathological examination suggested that the final stage in the process of cardiac muscle degeneration to be severe myocarditis. This was found in two lobsters and recognized as white nodular lesions in the hearts. Although some animated lobsters had severe cardiac lesions, they were
Table 1. $\chi^{2}$ analysis between the clinical signs and the histopathological findings-I

\begin{tabular}{|c|c|c|c|}
\hline \multirow{2}{*}{$\begin{array}{l}\text { Degeneration and } \\
\text { necrosis of } \\
\text { the myocardium }\end{array}$} & \multicolumn{2}{|c|}{ Clinical signs*1 } & \multirow{2}{*}{ Total } \\
\hline & $\begin{array}{l}\text { Animated and } \\
\text { slight }\end{array}$ & $\begin{array}{l}\text { Moderate and } \\
\text { severe }\end{array}$ & \\
\hline Slight*2 & $10^{* 3}$ & 8 & 18 \\
\hline Moderate and severe*2 & 3 & 18 & 21 \\
\hline Total & 13 & 26 & 39 \\
\hline $\begin{array}{l}\chi^{2} \mathrm{cal}=7.4 \text {. Degree of freed } \\
\text { At the degree of freedom is } \\
\text { are } 3.841 \text { and } 6.635 \text {, respective } \\
* 1 \text { : Clinical signs were cla } \\
\text { degree of weakness. } \\
{ }^{2}: \text { Subjective degrees on } \\
{ }^{* 3}: \text { Numbers of the lobste }\end{array}$ & $\begin{array}{l}m ;(2-1)(2-1)=1 \\
\text { ne, } \chi^{2} \text { value corres } \\
\text { sified subjectively in } \\
\text { e histopathological }\end{array}$ & $\begin{array}{l}\text { onding to } p=0.05 \\
\text { o four categories } \\
\text { hanges. }\end{array}$ & $\begin{array}{l}p=0.01 \\
\text { cording to }\end{array}$ \\
\hline
\end{tabular}

Table 2. $\chi^{2}$ analysis between the clinical signs and the histopathological findings-II

\begin{tabular}{|c|c|c|c|}
\hline \multirow{2}{*}{$\begin{array}{l}\text { Cellular } \\
\text { infiltration }\end{array}$} & \multicolumn{2}{|c|}{ Clinical signs*1 } & \multirow[b]{2}{*}{ Total } \\
\hline & $\begin{array}{c}\text { Animated and } \\
\text { slight }\end{array}$ & $\begin{array}{c}\text { Moderate and } \\
\text { severe }\end{array}$ & \\
\hline No observation and slight*2 & $11^{* 3}$ & 13 & 24 \\
\hline Moderate and severe*2 & 2 & 13 & 15 \\
\hline Total & 13 & 26 & 39 \\
\hline \multicolumn{4}{|c|}{$\begin{array}{l}\chi^{2} \mathrm{cal}=4.3 \text {. Degree of feedom; }(2-1)(2-1)=1 . \\
\text { At the degree of freedom is one, } \chi^{2} \text { values corresponding to } p=0.05 \text { is } 3.841 \text {. } \\
{ }^{* 1}: \text { Clinical signs were classified subjectively into four categories according to } \\
\text { degree of weakness. } \\
*^{* 2}: \text { Subjective degrees of the histopathological changes. } \\
{ }^{* 3}: \text { Numbers of the lobsters. }\end{array}$} \\
\hline
\end{tabular}

primarily found in the weakened lobsters. The results of $\chi^{2}$ analysis also supports this finding. From these findings, it was considered that the cardiac lesions might be a primary cause of the weakness in the present case.

While it was not possible to show the detailed pathogenesis of edematic swelling of the abdominal segments, it is possible to consider that this clinical feature may indicate the existence of the disease, because the feature was found only in severely weakened lobsters with moderate or severe cardiac lesions. In conclusion, the disease characterized by degeneration and necrosis of cardiac muscles resulted in myocarditis, and appears to prevail in clusters of free-living wild spiny lobsters. 